\title{
Complications after breast reconstruction with alloplastic material in breast cancer patients submitted or not to post mastectomy radiotherapy
}

\author{
Silvia Radwanski Stuart ${ }^{1}{ }^{1,2}$, Alexandre Mendonça Munhoz ${ }^{2}$, Cristiane L.G. Chaves ${ }^{1 \star}$, Eduardo Montag ${ }^{2}$, \\ Thalita C.S. Cordeiro ${ }^{1}$, Tatiana Taba Fuzisaki ${ }^{1 \star \star}$, Gustavo N. Marta ${ }^{1}$, Heloisa A. Carvalho ${ }^{1,2}$ \\ ${ }^{1}$ Department of Radiology and Oncology — Radiotherapy, Instituto do Câncer do Estado de São Paulo (ICESP), Brasil \\ ${ }^{2}$ Instituto de Radiologia (INRAD) - Hospital das Clinicas HCFMUSP, Faculdade de Medicina, Universidade de Sao Paulo, Sao Paulo, Brasil \\ ${ }^{3}$ Department of Plastic Surgery, Division of Breast Reconstruction, Instituto do Câncer do Estado de São Paulo (ICESP), \\ Faculdade de Medicina FMUSP, Universidade de Sao Paulo, Sao Paulo, Brasil \\ *Present address: Department of Radiation Oncology - Grupo Oncoclínicas, Rio de Janeiro, Brazil \\ **Present address: Department of Radiation Oncology Unimed Bauru Hospital, Bauru, Brazil
}

\begin{abstract}
Background and purpose: Breast reconstruction following mastectomy is a relevant element of breast cancer treatment. The purpose of this study was to evaluate the influence of radiotherapy (RT) on local complications in patients with breast cancer that had undergone breast reconstruction with alloplastic material.

Materials and methods: Retrospective study of breast cancer patients submitted to mastectomy and breast reconstruction from 2009 to 2013. Clinical and treatment variables were correlated with early and late complications.

Results: 251 patients were included; mean age was 49.7 ( 25 to 78 ) years. Reconstruction was immediate in $94 \%$ of the patients, with $88 \%$ performed with a temporary tissue expander. Postoperative radiotherapy (RT) was delivered to 167 patients (66.5\%). Early complications were present in $26.3 \%$ of the patients. Irradiated patients presented $5.4 \%$ incidence of late complications versus $2.4 \%$ for non-irradiated patients $(p=0.327$ ). Diabetes ( $\mathrm{OR}=3.4195 \% \mathrm{Cl}: 1.23-9.45, \mathrm{p}=0.018)$ and high body mass index (BMI) $(\mathrm{OR}=2.65 ; 95 \% \mathrm{Cl}: 1.60-4.37, \mathrm{p}<0.0001)$ were the main risk factors. The overall incidence of late complications was $4.4 \%$, with predominance of severe capsular contracture (8/11). Arterial hypertension (OR=4.78; $95 \% \mathrm{Cl}: 1.97-11.63, \mathrm{p}=$ 0.001), $\mathrm{BMI}(\mathrm{OR}=0.170 ; 95 \% \mathrm{Cl}: 0.048-0.607, \mathrm{p}=0.006)$ and implant placement $(\mathrm{OR}=3.55 ; 95 \% \mathrm{Cl}: 1.26-9.99, \mathrm{p}=0.016)$ were related to late complications.

Conclusions: The overall rate of complications was low in this population. Radiotherapy delivery translated into a higher but not statistically significant risk of late complications when compared with the non-irradiated patients. Already well-known clinical risk factors for complications after breast reconstruction were identified.
\end{abstract}

Key words: breast neoplasm; reconstruction; alloplastic material; acute toxicities; radiotherapy; implants; tissue expander; outcome; complications

Rep Pract Oncol Radiother 2021;26(5):730-739

Address for correspondence: Silvia R Stuart, MD, INRAD — Hospital das Clinicas HCFMUSP, Rua Dr. Ovídio Pires de Campos, 75, Portaria 3, Cerqueira César, São Paulo - SP, 05403-010, Brasil, tel: 5511 26616722; e-mail: silvia.stuart@hc.fm.usp.br 


\section{Introduction}

Radiation is paramount for the proper treatment of breast cancer, with a positive impact on both, local control, and survival $[1,2]$. It is essential in breast-conserving therapies, as well as for more advanced tumors that require a mastectomy.

With the developments achieved by breast cancer treatments, nowadays, even more complex cases may expect long-term survival as seen in the Hera Trial adding Trastuzumab to patients with HER2-positive early breast cancer [3]. Thus, lowering late toxicity is imperative. Radiation delivery techniques by themselves have improved significantly over the years. The introduction of advanced irradiation techniques, such as intensity-modulated radiotherapy (IMRT), hypofractionated schedules, and partial breast irradiation, has contributed to the reduction in side effects $[4,5]$. Still, radiation has significant damaging effects on breast reconstruction that may take months to several years to become fully apparent.

Breast reconstruction following mastectomy continues to be a valuable element of breast cancer treatment and plastic surgery practice $[6,7]$. Among the main reconstructive procedures, expander/implant remains more prevailing than autologous reconstruction, accounting for nearly $70 \%$ of all procedures [8-10]. Given the high incidence of breast reconstruction, efforts should be made to optimize surgical outcomes and maintain patient safety [10].

Due to quality-of-life issues and benefits, immediate breast reconstruction (performed at the time of mastectomy) has steadily increased during the past two decades $[6,7,11]$. While only $15 \%$ of women who underwent mastectomy had immediate reconstruction in 2011, this number increased to about $40 \%$ in 2018 [11-13]. This is an important gain since immediate reconstruction can improve the psychosocial and physical consequences of mastectomy [14]. Besides, immediate reconstruction is technically easier to perform than delayed reconstruction due to decreased scarring and preservation of the breast contours.

These reconstructive trends have concurred with the increasing use of post-mastectomy radiotherapy (RT) in women with locally advanced breast cancer [15-17]. RT induces tissue injury that can be categorized as acute or late/chronic. The spectrum of acute injury includes mostly mild to severe skin reactions, such as erythema, edema, desquamation, hyperpigmentation, and ulceration [18]. Any degree of acute radiation dermatitis occurs in upward of $85 \%$ of the treated patients. The chronic or late injury involves skin atrophy, dryness, telangiectasia, depigmentation, and achromia [19]. Fibrosis of the skin and subcutaneous tissues may occur and, according to the severity of the fibrosis, pain and restricted movement of the arm may be observed $[20,21]$. The late changes from radiation can take months to years to fully manifest [22]. With the high rates of local control and long-term survival observed in breast cancer patients, concerns about both aesthetic and clinical effects of irradiation in a reconstructed breast, either with autologous tissue or alloplastic implants are also increasing. Furthermore, data from the previous series demonstrate a lower rate of complications and better aesthetic outcomes in patients who did not receive RT before implant reconstruction compared with those who did receive RT before completing implant reconstruction [23]. Thus, evaluating the potential risk factors of complications following breast reconstruction aggregates a valuable part of the preoperative planning and decision-making process.

Therefore, the present study was undertaken to critically evaluate the outcome of breast reconstruction using alloplastic tissue and the influence of RT on local complications and provide radiation oncologists and plastic surgeons with relevant data needed to properly counsel patients in their option for implant-based reconstruction.

\section{Materials and methods}

This study received approval from the ethics and research committee of the Hospital das Clínicas, Faculdade de Medicina, University of Sao Paulo, Brazil.

This is a retrospective single-center study of breast cancer patients submitted to postoperative RT who underwent a mastectomy, followed by immediate reconstruction with tissue expansion and silicone gel breast implant performed by a single team of plastic surgeons, treated between 2009 and 2013 in a public/university hospital. All patients with a breast cancer diagnosis were first seen by a multidisciplinary team and, according to the breast volume/ptosis, were evaluated by the plastic 
surgeon who indicated the incision and reconstruction with an appropriate technique. A control group was composed of breast cancer patients treated during the study period submitted to the same surgical procedures but not to RT.

All patients underwent staged breast reconstruction. Tissue expansion was first performed with a macrotexture, anatomically shaped tissue expander device (Allergan 133 style - Allergan, Santa Barbara, Calif.) or Mentor 2500 style (Mentor, Santa Barbara, Calif.) tissue expanders.

Tissue expanders were placed fully submuscular (beneath the pectoralis major and serratus muscles) during the breast cancer surgery. Tissue expanders were filled before irradiation, to prevent major impacts on skin elasticity due to RT.

Postoperative radiation was planned with a three-dimensional conformal technique using a forward field-in-field strategy to reduce dose inhomogeneity and hot spots (maximum dose $<12-15 \%)$. At this moment clinical stage before surgery or chemotherapy defined the volumes used for target volume delineation in the setting of postmastectomy RT after implant-based immediate reconstruction using Radiation Therapy Oncology Group (RTOG) guidelines [24].

Only patients with at least 2 years of follow-up after the end of treatment were included. Demographic, clinical, and treatment data (surgery, systemic treatment, and RT) were retrospectively collected, as were data on the occurrence of complications and pre-existing comorbidities. Data regarding complications were mostly those related to surgery (i.e., seroma, infection, implant extrusion, capsular contracture). Postoperative complications were considered as early when occurred any time before RT, up to 6 months after surgery. Late complications were those observed six months after surgery, or after the end of RT, and were the main focus of this study.

\section{Statistical analysis}

The primary endpoint was the occurrence of either early or late complications.

Requirements for a new surgical intervention or implant loss were considered severe complications.

Descriptive and frequency analyses were performed. Correlations were evaluated by Pearson's chi-square method. Linear regression with a backward stepwise method was used for the multivariate analysis. In this analysis, variables with a significance of at least $10 \%$ were kept in the model, as well as those already known as clinically related to complications (such as diabetes mellitus, arterial hypertension, body mass index (BMI), and smoking). Radiotherapy was also included in the model. Odds ratios (OR) with the respective 95\% confidence intervals (95\% CI) for the selected variables were calculated by logistic regression. IBM SPSS Statistics Software v.20 (Chicago, Illinois) was used for the analysis with the significance level set at $5 \%(\mathrm{p} \leq 0.05)$.

\section{Results}

The entire cohort consisted of 251 patients, and 275 breasts ( 24 patients with bilateral tumors) were evaluated, with a mean age of 49.7 (25 to 78 ) years. Details of patients' and treatments' characteristics are presented in Table 1. Most patients (92.4\%) presented high $\mathrm{BMI} \geq 25 \mathrm{~kg} / \mathrm{m}^{2}$; few had diabetes mellitus (7.2\%), $34.7 \%$ hypertension, and $28.6 \%$ smoking history. The majority presented in initial stages, I through IIB (56.2\%), with 11.5\% ductal carcinomas in situ.

Modified radical mastectomy was the main surgical approach (68.5\%), with immediate reconstruction in $94 \%$ of the patients, $88 \%$ with a temporary tissue expander. Twenty-five (10\%) patients were also submitted to contralateral mastoplasty for symmetrization. The mean expansion volume was $546.2 \mathrm{~mL}$ ( $165 \mathrm{~mL}$ to $800 \mathrm{~mL}$ ) with $75 \%$ of the patients having at least $450 \mathrm{~mL}$ expansion.

Preoperative chemotherapy was performed in $35.8 \%$ of the patients and postoperative in $42.7 \%$. Patients that had received adjuvant chemotherapy presented $31 \%$ of any acute complications and $2 \%$ of late complications. Preoperative CT represented a protective factor for early complications ( $\mathrm{p}=0.001$, univariate analysis), with $13.3 \%$ incidence, compared to $30.8 \%$ for adjuvant CT. Patients who did not receive CT presented $38.9 \%$ of early complications (Supplementary File - Table S1).

Postoperative RT was delivered in 167 patients (66.5\%) and 176/275 breasts (64\%) with a dose of 50 Gy or 50.4 Gy. Supraclavicular/axillary fields radiotherapy was delivered to $137 / 167$ (82\%) patients. Those presented $19.7 \%$ of early complications and $8.7 \%$ of late complications. Irradiation or not of the supraclavicular/axillary fields was not selected as a risk factor in the multivariate analysis. 
Table 1. Patients, tumors, and treatment characteristics

\begin{tabular}{|c|c|c|c|c|}
\hline & $\begin{array}{l}\text { Overall } \\
(n=251)\end{array}$ & $\begin{array}{c}\text { RT } \\
(n=167)\end{array}$ & $\begin{array}{l}\text { No RT } \\
(n=84)\end{array}$ & $p$ \\
\hline Mean age (years) & $49.7(25-78)$ & $48.6(25-74)$ & $51.6(32-78)$ & 0.015 \\
\hline Median BMI $\left[\mathrm{kg} / \mathrm{m}^{2}\right]$ & $27.2(16.2-43.2)$ & $27.7(17.9-41.1)$ & $26.5(16.2-43.2)$ & 0.177 \\
\hline Diabetes mellitus & $18(7.2 \%)$ & $12(7.2 \%)$ & $6(7.1 \%)$ & 0.930 \\
\hline Hypertension & 87 (34.7\%) & 60 (35.9\%) & $27(32.1 \%)$ & 0.485 \\
\hline Smoking history & 74 (29.4\%) & 52 (31.1\%) & $22(26.2 \%)$ & 0.587 \\
\hline $\begin{array}{l}\text { Treated side } \\
\text { Right } \\
\text { Left } \\
\text { Bilateral }\end{array}$ & $\begin{array}{c}108(43.0 \%) \\
119(47.4 \%) \\
24(9.6 \%)\end{array}$ & $\begin{array}{c}75(44.9 \%) \\
82(49.1 \%) \\
10(6.0 \%)\end{array}$ & $\begin{array}{l}33(39.3 \%) \\
37(44.0 \%) \\
14(16.7 \%)\end{array}$ & 0.025 \\
\hline $\begin{array}{l}\text { Histologic type } \\
\text { DCIS } \\
\text { IDC } \\
\text { ILC } \\
\text { Others } \\
\text { No tumor* }\end{array}$ & $\begin{array}{c}27(10.7 \%) \\
179(71.3 \%) \\
17(6.8 \%) \\
22(8.8 \%) \\
6(2.4 \%)\end{array}$ & $\begin{array}{c}13(7.8 \%) \\
129(77.2 \%) \\
9(5.4 \%) \\
14(8.4 \%) \\
2(1.2 \%)\end{array}$ & $\begin{array}{c}14(16.7 \%) \\
50(59.5 \%) \\
8(9.5 \%) \\
8(9.5 \%) \\
4(4.8 \%)\end{array}$ & 0.026 \\
\hline $\begin{array}{l}\text { Immunohistochemistry } \\
\text { "Luminal-like" } \\
\text { Triple negative } \\
\text { Her2 }\end{array}$ & $\begin{array}{l}183(72.9 \%) \\
33(13.2 \%) \\
35(13.9 \%)\end{array}$ & $\begin{array}{l}125(74.8 \%) \\
25(15.0 \%) \\
17(10.2 \%)\end{array}$ & $\begin{array}{c}58(69.0 \%) \\
8(9.5 \%) \\
18(21.5 \%)\end{array}$ & 0.017 \\
\hline $\begin{array}{l}\text { Stage }^{\#} \\
\text { In situ } \\
\text { I-IIB } \\
\text { III }\end{array}$ & $\begin{array}{c}27(11.5 \%) \\
141(56.2 \%) \\
83(33.1 \%)\end{array}$ & $\begin{array}{c}13(7.8 \%) \\
81(48.5 \%) \\
74(44.3 \%)\end{array}$ & $\begin{array}{c}14(16.7 \%) \\
61(72.6 \%) \\
9(10.7 \%)\end{array}$ & $<0.0001$ \\
\hline $\begin{array}{l}\text { Surgery } \\
\text { Mastectomy } \\
\text { SSM or NSP } \\
\text { Quadrantectomy }\end{array}$ & $\begin{array}{c}172(68.5 \%) \\
78(31.1 \%) \\
1(0.4 \%)\end{array}$ & $\begin{array}{c}120(71.9 \%) \\
46(27.5 \%) \\
1(0.6 \%)\end{array}$ & $\begin{array}{c}52(61.9 \%) \\
32(38.1 \%) \\
-\end{array}$ & 0.109 \\
\hline $\begin{array}{l}\text { Reconstruction timing } \\
\text { Immediate } \\
\text { Late }\end{array}$ & $\begin{array}{c}236(94.0 \%) \\
15 \text { (6.0\%) }\end{array}$ & $\begin{array}{c}160 \text { (95.8\%) } \\
7(4.2 \%)\end{array}$ & $\begin{array}{c}75(89.3 \%) \\
9(10.7 \%)\end{array}$ & 0.027 \\
\hline $\begin{array}{l}\text { Reconstruction material } \\
\text { TEIV } \\
\text { TERV } \\
\text { Expander Implant } \\
\text { Prosthesis }\end{array}$ & $\begin{array}{c}116(46.2 \%) \\
111(44.2 \%) \\
7(2.8 \%) \\
17(6.8 \%)\end{array}$ & $\begin{array}{c}85(50.9 \%) \\
71(42.5 \%) \\
3(1.8 \%) \\
8(4.8 \%)\end{array}$ & $\begin{array}{c}31(36.9 \%) \\
40(47.6 \%) \\
4(4.8 \%) \\
9(10.7 \%)\end{array}$ & 0.060 \\
\hline $\begin{array}{l}\text { Reconstruction material } \\
\text { TEIV or TERV } \\
\text { Permanent Implant }\end{array}$ & $\begin{array}{c}221(88.0 \%) \\
30(12.0 \%)\end{array}$ & $\begin{array}{c}152 \text { (91.0\%) } \\
15 \text { (9.0\%) }\end{array}$ & $\begin{array}{l}69(82.1 \%) \\
15(17.9 \%)\end{array}$ & 0.041 \\
\hline $\mathrm{CL}$ mastoplasty & 25 (9.9\%) & $13(7.7 \%)$ & $12(1,4 \%)$ & 0.038 \\
\hline $\begin{array}{l}\text { Chemotherapy } \\
\text { None } \\
\text { Neoadjuvant } \\
\text { Adjuvant }\end{array}$ & $\begin{array}{c}54(21.5 \%) \\
90(35.8 \%) \\
107(42.7 \%)\end{array}$ & $\begin{array}{l}21(12.6 \%) \\
78(46.7 \%) \\
68(40.7 \%)\end{array}$ & $\begin{array}{l}33(39.3 \%) \\
12(14.3 \%) \\
39(46.4 \%)\end{array}$ & $<0.0001$ \\
\hline
\end{tabular}

RT — radiotherapy; DCIS — ductal carcinoma in situ; IDC — invasive carcinoma noe; ILC — invasive lobular carcinoma; SSM — skin-sparing mastectomy; NSP — nipple-sparing mastectomy; TEIV — tissue expander with included valve; TERV — tissue expander with remote valve; $\mathrm{CL}$ - contralateral; *patients submitted to prophylactic surgery; "the highest stage was considered for bilateral disease 
Table 2. Incidence of complications in 251 patients. Early complications were considered as those occurring at any time after surgery and before radiotherapy (RT) or up to 6 months after surgery in patients not submitted to RT

\begin{tabular}{|c|c|c|c|c|}
\hline & $\begin{array}{c}\text { Overall } \\
(n=251)\end{array}$ & $\begin{array}{c}\text { RT } \\
(n=167)\end{array}$ & $\begin{array}{c}\text { No RT } \\
(n=84)\end{array}$ & p \\
\hline Early complications & $66(26.3 \%)$ & $40(23.9 \%)$ & $26(30.9 \%)$ & 0.235 \\
\hline Seroma & $59(23.5 \%)$ & 45 (26.9\%) & 14 (16.7\%) & 0.700 \\
\hline Hematoma & $2(0.8 \%)$ & - & $2(2.4 \%)$ & 0.045 \\
\hline Local infection & $18(7.2 \%)$ & $9(5.4 \%)$ & $9(10.7 \%)$ & 0.123 \\
\hline Partial necrosis & $12(4.8 \%)$ & $8(4.8 \%)$ & $4(4.7 \%)$ & 0.992 \\
\hline Partial dehiscence $(<1 / 3)$ & $2(0.8 \%)$ & $2(1.2 \%)$ & - & 0.314 \\
\hline Total dehiscence (> 1/3) & $1(0.4 \%)$ & $1(0.6 \%)$ & - & 0.477 \\
\hline Extrusion & $1(0.4 \%)$ & $1(0.6 \%)$ & - & 0.477 \\
\hline More than one & $14(5.6 \%)$ & $8(4.8 \%)$ & $6(7.1 \%)$ & 0.443 \\
\hline Second surgical intervention required & $36(14.3 \%)$ & $25(15.0 \%)$ & $11(13.1 \%)$ & 0.689 \\
\hline Implant loss & $25(10.0 \%)$ & $16(9.6 \%)$ & $9(10.7 \%)$ & 0.777 \\
\hline Late complications & $11(4.4 \%)$ & $9(5.4 \%)$ & $2(2.4 \%)$ & 0.327 \\
\hline Local infection & $2(0.8 \%)$ & $2(1.2 \%)$ & - & 0.314 \\
\hline Extrusion & $1(0.4 \%)$ & $1(0.6 \%)$ & - & 0.477 \\
\hline Severe capsular contracture & $8(3.2 \%)$ & $6(3.6 \%)$ & $2(2.4 \%)$ & 0.606 \\
\hline More than one & $1(0.4 \%)$ & $1(0.6 \%)$ & - & 0.477 \\
\hline
\end{tabular}

Ninety-five (37.8\%) patients presented 125 (50.8\%) early complications. Seroma was the most frequent complication, observed in $23.5 \%$ of all patients. Surgical intervention due to early complications was required in 14.3\% (36 patients) and 10\% (25 patients) who had lost their implants. Only 19 (7.6\%) patients presented 21 late complications, 15 of whom received postoperative RT. Among the patients that were submitted to surgery only (no chemo or radiotherapy), $16 \%$ presented acute complications and about $10 \%$ severe late complications. Overall, there were no significant differences in the incidence of early or late complications between the groups submitted or not to RT (Tab. 2).

As the incidence of complications occurred in the same number of breasts and patients, and some variables are related to the clinical characteristics of the patients, subsequent analyzes were performed considering only the total number of 251 patients.

In the univariate analysis, 50 years or more, BMI $\geq 25 \mathrm{~kg} / \mathrm{m}^{2}$ (overweight or obesity), diabetes mellitus, smoking history, immediate reconstruction, temporary expanders, adjuvant chemotherapy, were related to a higher risk of acute toxicity $(\mathrm{p}<0.05)$ and, preoperative chemotherapy was a protective factor for early complications (Table 3 ). In the multivariate analysis, all the mentioned variables except for reconstruction timing ( $94 \%$ were immediate) were included, and arterial hypertension and postoperative RT were also added as risk factors for early toxicity (Tab. 4).

Diabetes $(\mathrm{p}=0.015)$ and obesity $(\mathrm{p}=0.001)$ were selected as higher risk factors for early toxicity and preoperative chemotherapy, as a protective factor $(\mathrm{p}=0.001)$. The delivery of RT was associated with twice the late complication rate ( $5 \% v s .2 .4 \%)$, but the difference was not significant ( $\mathrm{p}=0.327$ ) (Supplementary File - Table S1). Focusing on the most severe complications (second surgical intervention required or implant loss), acute infection was included in the model and selected as an important related factor in both scenarios $(\mathrm{p}=0.023$ and $<0.0001$, respectively). Analyzing infection as a separate variable, it was mostly present in patients with diabetes mellitus ( $\mathrm{p}=0.026)$ and obesity $(\mathrm{p}=0.082)$, and these patients were more prone to require a second surgical intervention $(\mathrm{p}=0.034$ and 0.007 , respectively).

Still, patients with BMI $\geq 30 \mathrm{~kg} / \mathrm{m}^{2}$ presented a higher risk for implant loss $(\mathrm{p}<0.0001)$. A sepa- 
rate regression analysis was performed with infection as an endpoint. Diabetes mellitus ( $p=0.026)$ was selected as a risk factor, and preoperative chemotherapy represented a protective factor for early infection $(\mathrm{p}=)$. RT was not selected as a risk factor for these more severe complications (Supplementary File - Table S2).

None of the variables were related to late toxicity in the univariate analysis (Supplementary File - Table S1). The multivariate analysis detected $\mathrm{BMI} \geq 30 \mathrm{~kg} / \mathrm{m}^{2}(\mathrm{p}=0.018)$ and arterial hypertension $(\mathrm{p}=0.04)$ as independent risk factors for late complications; implant placement was marginally significant ( $\mathrm{p}=0.056$, subpectoral total with higher risk) (Supplementary File - Table S2).

As observed for all early complications, besides twice the incidence of late complications in the irradiated group, no statistically significant correlation with irradiation was detected.

The odds ratios for having early complications, a requirement for a second surgical intervention, implant loss, and late complications are presented in Supplementary File - Table S3. RT did not have a significant impact in any of these endpoints.

\section{Discussion}

Debates surround the timing and method of reconstruction in the setting of post-mastectomy RT [21]. For alloplastic tissue breast reconstruction, the discussion relates to irradiating the tissue expander or the final implant. Some authors have advocated against implant reconstruction in patients who received or are expected to receive radiation $[25,26]$. For autologous reconstruction, the debate centers on directly irradiating the flap or delaying the reconstruction until after radiation. It is important to remember that radiation protocols vary greatly from one institution to another, regarding the use of bolus, boost prescription, timing, and others, which can make comparison difficult as radiation has dose-dependent effects [22, 27]. When we evaluated more severe complications, diabetes, obesity, and arterial hypertension were selected as independent risk variables. Neoadjuvant chemotherapy has been shown to negatively affect postoperative outcomes compared with patients who did not receive such treatment [28]. However, a protective effect of neoadjuvant chemotherapy regarding more severe acute complications (im- plant loss) and infection was observed in our study (Supplementary File - Table S1). Since infection is and was related to more severe complications, probably, tumor size decrease and downstaging of tumors may minimize surgical trauma, or even, avoidance of the immune impact caused by chemotherapy after surgery may lower the risk of postoperative infections and, consequently, decrease the early complications rates. Of note, the rate of patients that received preoperative chemotherapy was higher in the RT group (Tab. 1). In addition, patients that did not receive any chemotherapy presented a higher early complication rate $(38.9 \%)$ when compared to those that received neoadjuvant $(13.3 \%)$ or adjuvant chemotherapy $(30.8 \%)$ (Supplementary File - Table S1).

About $30 \%$ of our cohort were smokers. Smoking is related to a higher grade of complications in elective plastic surgeries [29]. In our analysis, we did not find any correlation with complications.

When analyzed separately, the acute infection was more incident in diabetic patients and in patients with high BMI, as expected. Together with higher age, hypertension, and smoking, these risk factors were already detected in a previous study [30]. The great majority of the present cohort was submitted to immediate reconstruction with a temporary tissue expander. Thus, the timing of reconstruction was excluded from further analysis since it would be more related to early complications. The policy of our department is to perform immediate reconstruction to keep the patient's self-esteem up. However, the 2nd intervention is only performed after the end of RT, to minimize delays in RT treatment and for corrections of contractures due to irradiation later on.

In 2013, Lam et al. [22] published a systematic review attempting to determine optimal sequencing for radiation in two-stage reconstruction. Overall, 12 studies were included (only 1 prospective), which pooled 715 irradiated patients and 1,138 not irradiated patients. Radiation increased reconstructive failure $(18.6 \% v s .3 .1 \%$; $<<0.0001)$, and more specifically, failure occurred at higher rates not only when RT was applied to the expander $(29.7 \% v s$. $5.0 \% ; \mathrm{p}<0.00001)$, but also when delivered directly to the implant $(7.7 \%$ vs. $1.5 \% ; \mathrm{p}=0.0003)$. This review also noted an increased risk of severe capsular contracture for both radiation to the tissue expander $(8.9 \%$ vs. $0.5 \%$; $\mathrm{p}=0.01)$ and the perma- 
nent implant ( $7.9 \%$ vs. $0.2 \% ; \mathrm{p}=0.002)$, although no difference in timing was noted.

The timing of RT, pre or post-reconstruction was also addressed by some authors with no significant difference between them [31,32]. Only a small percentage of patients (6\%) in our series received reconstruction after RT. Thus, no conclusion can be made based on this finding. All the other studied factors, such as the type of oncological surgery, implant placement, contralateral mastoplasty, and implant volume, did not impact the reconstruction outcome.

More recently, the type of reconstruction was addressed in a large patient cohort submitted or not to RT. The effects of single-stage direct-to-implant, tissue expander/implant, and autologous reconstruction were compared between irradiated and not irradiated patients. Irradiation increased the risk of breast reconstruction complications overall, but single-stage or autologous reconstruction presented lower complication rates when compared with the tissue expander/implant approach [33].

We describe here a large cohort of breast cancer patients with alloplastic reconstruction only, with a minimum follow-up of 24 months. Concerning the reconstruction technique, the option of a tissue expander is determined by the patient's anatomy and surgeon-related issues and availability. Factors related to the patient, such as anatomy, BMI, breast volume and ptosis, and quality of the oncological surgery may influence the plastic surgeon's option for the reconstructive procedure and also the risk of postoperative complications $[6,7]$. In our series, the overall incidence of late complications was $4.4 \%$, with the predominance of severe capsular contracture (8/11), as observed in other publications [34]. Nevertheless, this is an extremely low rate if one considers the inherent risk of capsular contracture of 5 to $30 \%$ [35] in both non-irradiated and irradiated patients. We must admit, however, that less severe complications, such as mild to moderate capsular contracture and radiodermatitis during radiotherapy treatment, were not evaluated in this cohort, due to the retrospective nature of our study. Data regarding less severe late complications were not always available and, thus, we decided not to rely on results based on the lack of this information. We consider this a major limitation of our study. Nevertheless, irradiated patients did not present a statistically significantly higher rate of complications. The influence of radiodermatitis, however, may not be neglected, and may play an important role in surgical complications, mostly after tissue expansion, and could be the object of future research.

Still, as for early complications, high BMI and hypertension were independent risk factors for late complications. Implant placement presented an OR of 3.5 for late complications (Supplementary File - Table S3), which may suggest that this low contracture rate must be related to the surgical technique with minor trauma in the displacement of the pectoralis major muscle, and total coverage of the expander with myocutaneous flaps, which decreases the risk of infection and decreases the inflammatory process of the muscle [21].

The present study has other limitations that should be recognized. Our sample is retrospective and not randomized, and there is a factor of selection bias that cannot be excluded. Our satisfactory outcomes result from collaboration with the oncological surgeon in terms of incision selection and an adequate skin flap dissection. We understand that this technical aspect is not often observed in clinical practice. It is, therefore, our opinion that our results are only attainable if the indication for these techniques and the team approach is strictly followed. It is well known that increasing experience with oncological and reconstruction procedures decreases postoperative complications [36]. Finally, long-term complications (reoperation rates, secondary and tertiary reconstructions) and quality of life issues were not within the main endpoints of this analysis but would indeed be pertinent aspects of evaluation for future investigation. Although our previous experience indicates that breast reconstruction with autologous tissue is preferred when possible, in patients who are candidate for RT, for technical and medical aspects, not every patient is an appropriate candidate for these procedures. Furthermore, in some clinical situations, the need for adjuvant RT cannot always be predicted precisely before the surgical treatment. However, autologous reconstruction also can present RT-related complications, including fat necrosis, skin and muscular atrophy, and severe fibrosis $[6,7,25]$. Thus, in patients for whom adjuvant RT may be considered, multidisciplinary evaluation and close relation with the RT team is 
important to decide the appropriate reconstruction technique.

The most important finding of our study was the fact that besides RT delivery translated in twice the risk of late complications $(5.4 \% v s$. $2.4 \%$ ), this risk was still low and the difference, when compared with the non-irradiated patients, was not significant. RT delivery did not impact any of the other studied endpoints. A critical comparison of the present data with previous studies indicates that staged reconstruction associated with complete coverage of the implant with muscle, and the last generation of radiation therapy protocols do provide acceptable complication rates when alloplastic breast reconstruction is undertaken in irradiated patients. Hence, it has been our impression that favorable outcomes are possible for the group of patients who receive postoperative RT.

Already well-known clinical risk factors for complications after breast reconstruction were identified in the multivariate analysis. Therefore, patients with an indication of breast reconstruction with alloplastic material after mastectomy should be advised about keeping or reaching a BMI near normal (20-25 kg/m ${ }^{2}$ ), which may also contribute to a well-balanced blood glucose level. The institution policy is still to plan an immediate reconstruction since it delivers better acceptance and superior psychosocial results. Combined efforts between radiation oncologists and plastic surgeons should be accomplished to better comprehend the different breast reconstruction techniques and how RT influences outcomes and complications after immediate breast reconstruction.

\section{Conclusion}

A low rate of significant early complications was observed in this cohort, and preoperative chemotherapy represented a protective factor mainly for local infection. Infection was the most important factor related to a new surgical intervention or implant loss.

The rate of late complications was also very low, and although irradiated patients presented twice the risk for late complications this was still low, and not statistically significant. Pre-existing comorbidities were identified as independent risk factors for late complications.

\section{Conflict of interest}

S.R.S., C.L.G.C., E.M., T.C.S.C., T.T.F., G.N.M., H.A.C. - none declared; A.M.M is a Member of the Medical Advisory Board, Establishment Labs.

\section{Funding}

This research did not receive any specific grant from funding agencies in the public, commercial, or not-for-profit sectors. None of the authors has a financial interest in any of the products, devices, or drugs mentioned in this manuscript.

\section{References}

1. Darby S, McGale P, Correa C. Early Breast Cancer Trialists' Collaborative Group. Effect of radiotherapy after breast-conserving surgery on 10-year recurrence and 15-year breast cancer death: meta-analysis of individual patient data for 10801 women in 17 randomised trials. Lancet. 2011; 378(9804): 1707-1716, doi: 10.1016/s01406736(11)61629-2, indexed in Pubmed: 22019144.

2. McGale P, Taylor C, Correa C. Early Breast Cancer Trialists' Collaborative Group. Effect of radiotherapy after mastectomy and axillary surgery on 10-year recurrence and 20-year breast cancer mortality: meta-analysis of individual patient data for 8135 women in 22 randomised trials. Lancet. 2014; 383(9935): 2127-2135, doi: 10.1016/ s0140-6736(14)60488-8, indexed in Pubmed: 24656685.

3. Cameron D, Piccart-Gebhart MJ, Gelber RD, et al. Herceptin Adjuvant (HERA) Trial Study Team. 11 years' follow-up of trastuzumab after adjuvant chemotherapy in HER2positive early breast cancer: final analysis of the HERceptin Adjuvant (HERA) trial. Lancet. 2017; 389(10075): 11951205, doi: 10.1016/S0140-6736(16)32616-2, indexed in Pubmed: 28215665.

4. Haviland JS, Owen JR, Dewar JA, et al. START Trialists' Group. The UK Standardisation of Breast Radiotherapy (START) trials of radiotherapy hypofractionation for treatment of early breast cancer: 10-year follow-up results of two randomised controlled trials. Lancet Oncol. 2013; 14(11): 1086-1094, doi: 10.1016/S1470-2045(13)70386-3, indexed in Pubmed: 24055415.

5. Livi L, Meattini I, Marrazzo L, et al. Accelerated partial breast irradiation using intensity-modulated radiotherapy versus whole breast irradiation: 5-year survival analysis of a phase 3 randomised controlled trial. Eur J Cancer. 2015; 51(4): 451-463, doi: 10.1016/j.ejca.2014.12.013, indexed in Pubmed: 25605582.

6. Munhoz AM, Montag E, Filassi JR, et al. Immediate nippleareola-sparing mastectomy reconstruction: An update on oncological and reconstruction techniques. World J Clin Oncol. 2014; 5(3): 478-494, doi: 10.5306/wjco.v5.i3.478, indexed in Pubmed: 25114861.

7. Munhoz AM, Montag E, Gemperli R. Oncoplastic breast surgery: indications, techniques and perspectives. Gland Surg. 2013; 2(3): 143-157, doi: 10.3978/j.issn.2227684X.2013.08.02, indexed in Pubmed: 25083476.

8. American Society of Plastic Surgeons. 2018 National Plastic Surgery Statistics: Cosmetic and Reconstructive 
Procedure Trends. Arlington Heights, IL. https://www. plasticsurgery.org/documents/News/Statistics/2018/reconstructive-procedure-trends-2018.pdf (July 1st, 2020).

9. Alderman A, Gutowski K, Ahuja A, et al. Postmastectomy Expanderlmplant Breast Reconstruction Guideline Work Group. ASPS clinical practice guideline summary on breast reconstruction with expanders and implants. Plast Reconstr Surg. 2014; 134(4): 648e-655e, doi: 10.1097/ PRS.0000000000000541, indexed in Pubmed: 25357060.

10. Checketts JX, Gordon J, Crawford JH, et al. Is the Right Research Being Conducted to Advance Knowledge about Breast Reconstruction? An Analysis of the Research Pipeline. Plast Reconstr Surg. 2018; 141(3): 566-577, doi: $10.1097 /$ PRS.0000000000004107, indexed in Pubmed: 29481388.

11. Fisher B, Anderson S, Bryant J, et al. Twenty-year followup of a randomized trial comparing total mastectomy, lumpectomy, and lumpectomy plus irradiation for the treatment of invasive breast cancer. N Engl J Med. 2002; 347(16): 1233-1241, doi: 10.1056/NEJMoa022152, indexed in Pubmed: 12393820.

12. Jatoi I, Proschan MA. Randomized trials of breast-conserving therapy versus mastectomy for primary breast cancer: a pooled analysis of updated results. Am J Clin Oncol. 2005; 28(3): 289-294, doi: 10.1097/01.coc.0000156922.58631. d7, indexed in Pubmed: 15923803.

13. Lichter AS, Lippman ME, Danforth DN, et al. Mastectomy versus breast-conserving therapy in the treatment of stage I and II carcinoma of the breast: a randomized trial at the National Cancer Institute. J Clin Oncol. 1992; 10(6): 976-983, doi: 10.1200/JCO.1992.10.6.976, indexed in Pubmed: 1588378.

14. Al-Ghazal SK, Fallowfield L, Blamey RW. Comparison of psychological aspects and patient satisfaction following breast conserving surgery, simple mastectomy and breast reconstruction. Eur J Cancer. 2000; 36(15): 1938-1943, doi: 10.1016/s0959-8049(00)00197-0, indexed in Pubmed: 11000574.

15. Carlson RW, Allred DC, Anderson BO, et al. NCCN Breast Cancer Clinical Practice Guidelines Panel. Breast cancer. Clinical practice guidelines in oncology. J Natl Compr Canc Netw. 2009; 7(2): 122-192, doi: 10.6004/jnccn.2009.0012, indexed in Pubmed: 19200416.

16. Agarwal S, Kidwell KM, Farberg A, et al. Immediate Reconstruction of the Radiated Breast: Recent Trends Contrary to Traditional Standards. Ann Surg Oncol. 2015; 22(8): 2551-2559, doi: 10.1245/s10434-014-4326-x, indexed in Pubmed: 25564172.

17. Razdan SN, Cordeiro PG, Albornoz CR, et al. National Breast Reconstruction Utilization in the Setting of Postmastectomy Radiotherapy. J Reconstr Microsurg. 2017; 33(5): 312-317, doi: 10.1055/s-0037-1598201, indexed in Pubmed: 28235218.

18. Salvo N, Barnes E, van Draanen J, et al. Prophylaxis and management of acute radiation-induced skin reactions: a systematic review of the literature. Curr Oncol. 2010; 17(4): 94-112, doi: 10.3747/co.v17i4.493, indexed in Pubmed: 20697521.

19. El-Sabawi B, Carey JN, Hagopian TM, et al. Radiation and breast reconstruction: Algorithmic approach and evidence-based outcomes. J Surg Oncol. 2016; 113(8): 906-912, doi: 10.1002/jso.24143, indexed in Pubmed: 26750435.
20. Bentzen S, Thames H, Overgaard M. Latent-time estimation for late cutaneous and subcutaneous radiation reactions in a single-follow-up clinical study. Radiother Oncol. 1989; 15(3): 267-274, doi: 10.1016/0167-8140(89)90095-9, indexed in Pubmed: 2772254.

21. Sobti N, Weitzman RE, Nealon KP, et al. Evaluation of capsular contracture following immediate prepectoral versus subpectoral direct-to-implant breast reconstruction. Sci Rep. 2020; 10(1): 1137, doi: 10.1038/s41598-020-58094-4, indexed in Pubmed: 31980737.

22. Lam TC, Hsieh F, Boyages J. The effects of postmastectomy adjuvant radiotherapy on immediate two-stage prosthetic breast reconstruction: a systematic review. Plast Reconstr Surg. 2013; 132(3): 511-518, doi: 10.1097/ PRS.0b013e31829acc41, indexed in Pubmed: 23676964.

23. Ascherman JA, Hanasono MM, Newman MI, et al. Implant reconstruction in breast cancer patients treated with radiation therapy. Plast Reconstr Surg. 2006; 117(2): 359-365, doi: 10.1097/01.prs.0000201478.64877.87, indexed in Pubmed: 16462313.

24. Breast cancer atlas for radiation therapy planning: consensus definitions. http://www.rtog.org/CoreLab/ContouringAtlases/BreastCancerAtlas.aspx (October 24, 2011).

25. Evans G, Schusterman M, Kroll S, et al. Reconstruction and the Radiated Breast. Plastic and Reconstructive Surgery. 1995; 96(5): 1111-1115, doi: 10.1097/00006534199510000-00016, indexed in Pubmed: 7568487.

26. Forman DL, Chiu J, Restifo RJ, et al. Breast reconstruction in previously irradiated patients using tissue expanders and implants: a potentially unfavorable result. Ann Plast Surg. 1998; 40(4): 360-3; discussion 363, doi: 10.1097/00000637-199804000-00007, indexed in Pubmed: 9555989.

27. Eriksson M, Anveden L, Celebioglu F, et al. Radiotherapy in implant-based immediate breast reconstruction: risk factors, surgical outcomes, and patient-reported outcome measures in a large Swedish multicenter cohort. Breast Cancer Res Treat. 2013; 142(3): 591-601, doi: 10.1007/ s10549-013-2770-0, indexed in Pubmed: 24258257.

28. Frey JD, Choi M, Karp NS, et al. The Effect of Neoadjuvant Chemotherapy Compared to Adjuvant Chemotherapy in Healing after Nipple-Sparing Mastectomy. Plast Reconstr Surg. 2017; 139(1): 10e-19e, doi: 10.1097/ PRS.0000000000002841, indexed in Pubmed: 28027222.

29. Theocharidis V, Katsaros I, Sgouromallis E, et al. Current evidence on the role of smoking in plastic surgery elective procedures: A systematic review and meta-analysis. J Plast Reconstr Aesthet Surg. 2018; 71(5): 624-636, doi: 10.1016/j.bjps.2018.01.011, indexed in Pubmed: 29426809.

30. Matsumoto WK, Munhoz AM, Okada A, et al. Influence of advanced age on postoperative outcomes and total loss following breast reconstruction: a critical assessment of 560 cases. Rev Col Bras Cir. 2018; 45(2): e1616, doi: 10.1590/0100-6991e-20181616, indexed in Pubmed: 29617492.

31. Peled AW, Foster RD, Esserman LJ, et al. Increasing the time to expander-implant exchange after postmastectomy radiation therapy reduces expander-implant failure. Plast Reconstr Surg. 2012; 130(3): 503-509, doi: 10.1097/ PRS.0b013e31825dbf15, indexed in Pubmed: 22929235.

32. Ricci JA, Epstein S, Momoh AO, et al. A meta-analysis of implant-based breast reconstruction and timing of adjuvant ra- 
diation therapy. J Surg Res. 2017; 218: 108-116, doi: 10.1016/j. jss.2017.05.072, indexed in Pubmed: 28985836.

33. Naoum GE, Salama L, Niemierko A, et al. Single Stage Direct-to-Implant Breast Reconstruction Has Lower Complication Rates Than Tissue Expander and Implant and Comparable Rates to Autologous Reconstruction in Patients Receiving Postmastectomy Radiation. Int J Radiat Oncol Biol Phys. 2020; 106(3): 514-524, doi: 10.1016/j. ijrobp.2019.11.008, indexed in Pubmed: 31756414.

34. Jugenburg M, Disa JJ, Pusic AL, et al. Impact of radiotherapy on breast reconstruction. Clin Plast Surg. 2007;
34(1): 29-37; abstract v, doi: 10.1016/j.cps.2006.11.013, indexed in Pubmed: 17307069.

35. Momoh AO, Ahmed R, Kelley BP, et al. A systematic review of complications of implant-based breast reconstruction with prereconstruction and postreconstruction radiotherapy. Ann Surg Oncol. 2014; 21(1): 118-124, doi: 10.1245/s10434-013-3284-z, indexed in Pubmed: 24081801.

36. Purcell Jackson G, Tarpley JL. How long does it take to train a surgeon? BMJ. 2009; 339: b4260, doi: 10.1136/bmj. b4260, indexed in Pubmed: 19892790. 